\title{
Penfigóide Bolhoso Refractário em Paciente Infectado pelo Vírus da Imunodeficiência Humana
}

\author{
Chan I Thien', Mariana Rita de Novaes Fernandes², Fernanda Cabral ${ }^{3}$, Marcella D’Elia Novello4, Aline Lopes Bressan ${ }^{5}$, Juan Manuel \\ Piñeiro-Maceira ${ }^{6}$, Alexandre Carlos Gripp ${ }^{7}$ \\ 'Médica pós-graduanda do Serviço de Dermatologia do Hosp. Univ. Pedro Ernesto (HUPE), Univ. do Estado do Rio de Janeiro, Brasil \\ ${ }^{2}$ Médica residente do Serviço de Dermatologia do Hosp. Univ. Pedro Ernesto (HUPE), Univ. do Estado do Rio de Janeiro, Brasil \\ ${ }^{3}$ Médica dermatologista pelo Serviço de Dermatologia do Hosp. Univ. Pedro Ernesto (HUPE), Univ. do Estado do Rio de Janeiro, Brasil. \\ ${ }^{4}$ Médica dermatologista pelo Serviço de Dermatologia do Hosp. Univ. Pedro Ernesto (HUPE), Univ. do Estado do Rio de Janeiro, Brasil. \\ ${ }^{5}$ Professora voluntária do Serviço de Dermatologia do Hos. Univ. Pedro Ernesto (HUPE), Brasil \\ ${ }^{6}$ Médico do Serviço de Dermatologia Patológica do Hosp. Univ. Pedro Ernesto (HUPE), Univ. do Estado do Rio de Janeiro, Brasil. \\ Professor do Serviço de Patologia do Hosp. Univ. Clementino Fraga Filho (HUCFF), Univ. Federal do Rio de Janeiro, Brasil. \\ ${ }^{7}$ Professor auxiliar e Chefe do Serviço de Dermatologia do Hosp. Univ. Pedro Ernesto (HUPE), Brasil
}

RESUMO - Penfigóide bolhoso, a dermatose bolhosa subepidérmica auto-imune mais comum, é devida a auto-anticorpos contra partículas dos hemidesmosmas (BP180 e/ou BP230) e caracteriza-se por prurido e bolhas cutâneas tensas sobre base eritematosa ou pele normal. Afeta predominantemente idosos, por vezes com comorbilidades neurológicas ou neopláscias. A associação a infecção pelo vírus da imunodeficiência humana é rara. Relatamos o caso de uma paciente jovem $\mathrm{VIH}+$ em tratamento antirretroviral com carga viral indetectável e contagem normal de células T CD4+, que desenvolveu penfigóide bolhoso com lesões extensas, incluindo na mucosa oral, resistentes a vários pulsos de corticoides, corticoides orais e metotrexato, com melhora e estabilidade clínica apenas após uma infusão de rituximab, um anticorpo monoclonal anti-CD20.

PALAVRAS-CHAVE - Infecções por HIV; Penfigóide Bolhoso; Rituximab.

\section{Refractory Bullous Pemphigoid in HIV-Infected Patient}

ABSTRACT - Bullous pemphigoid, the most common autoimmune subepidermal blistering disease, is due to autoantibodies against BP180/230 present in the hemodesmosomes of the basal keratinocytes that typically causes pruritus and tense cutaneous bullae on an erythematous or normal skin It affects predominantly the elderly, often in association with neurologic or neoplastic disease. The association with the human immunodeficiency virus infection is rare. We present a case of a young VIH+ patient under antiretroviral therapy with undetectable viral load and normal CD4 + T-cell count who developed an extensive bullous pemphigoid refractory to pulses of corticosteroids, oral steroids and methotrexate and improved only after the infusion of rituximab, an anti-CD20 monoclonal antibody. KEYWORDS - HIV Infections; Pemphigoid, Bullous; Rituximab.

\section{INTRODUÇ̃̃O}

O penfigóide bolhoso ( $\mathrm{PB}$ ) é uma doença autoimune caracterizada por bolhas subepidérmicas, tensas, pruriginosas, que se localizam sobre a pele sã, eritematosa ou eritematoedematosa, que em cerca de $70 \%$ dos casos poupa as mucosas. ${ }^{1}$ Afeta predominantemente idosos, após os 60 anos, e associa-se frequentemente com doenças neurológicas ${ }^{1}$ e outras doenças autoimunes.

A associação com a infecção pelo vírus da imunodeficiência humana $(\mathrm{VIH})$ está pouco referenciada na literatura. Os autores relatam um caso de PB em paciente jovem com infecção VIH+ bem controlada com terapia antirretroviral (TARV) que se revelou refratário às terapias convencionais e respondeu bem ao rituximab.

\section{RELATO DE CASO}

Uma mulher de 33 anos diagnosticada com infecção por VIH há seis anos, iniciou quadro com lesões urticariformes pruriginosas e pústulas no tronco, com evolução de quatro meses (Fig. 1a). Durante internamento em serviço de Dermatologia
Correspondência: Chan I Thien

Avenida Rui Barbosa, 910, apt 702, Flamengo

Rio de Janeiro, RJ - CEP 22250-020, Brasil

E-mail: ithienchan@gmail.com

DOI: https://dx.doi.org/10.29021/spdv.76.1.739
Recebido/Received

04 Maio/May 2017

Aceite/Accepted

10 Outubro/October 2017 


\section{Caso Clínico}


Figura 1 - (A) lesões urticariformes pruriginosas e pustulosas no tronco, à data da admissão hospitalar; (B) bolhas tensas disseminadas no colo, tronco, membros e face após quatro dias de hospitalização.

surgiram bolhas tensas disseminadas no colo, tronco, membros, face e mucosa oral (Fig. 1b). A paciente estava sob TARV com tenofovir, lamivudina e efavirenz desde o diagnóstico, sem mudança recente de esquema terapêutico, com carga viral não-detectável e um número normal de células T CD4+ circulantes $\left(1063 / \mathrm{mm}^{3}\right.$ - valor de referência 537-1571 células $/ \mathrm{mm}^{3}$ ). Negava outras medicações e episódios anteriores semelhantes.

Ao exame dermatológico observaram-se múltiplas bolhas tensas de conteúdo citrino sobre base eritematosa acometendo grande área da superfície corporal, inclusive a face, com prurido importante. Tronco, membros superiores, mãos, punhos e pés eram os locais mais afetados. Na mucosa oral observou-se bolha hemorrágica e na mucosa genital apresentava lesões eritematosas exulceradas nos grandes lábios. Estas foram atribuídos a infecção oportunista pelo vírus herpes simplex e tiveram boa resposta ao tratamento com aciclovir intravenoso.

O hemograma completo, a função renal e hepática, sedimento urinário e radiografia de tórax estavam dentro da normalidade. A biópsia cutânea mostrou bolha subepidérmica

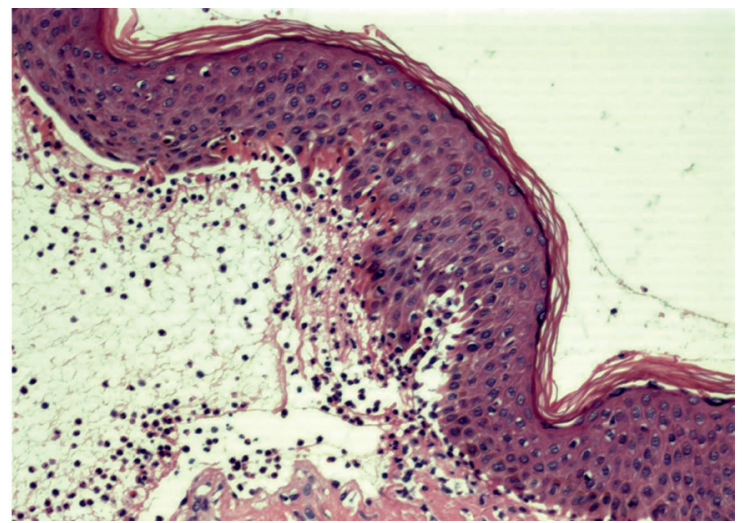

Figura 3 - Histopatologia de uma bolha com clivagem subepidérmica e infiltrado inflamatório rico em eosinófilos na derme e no interior da bolha $(\mathrm{HE}, 100 \mathrm{x})$.

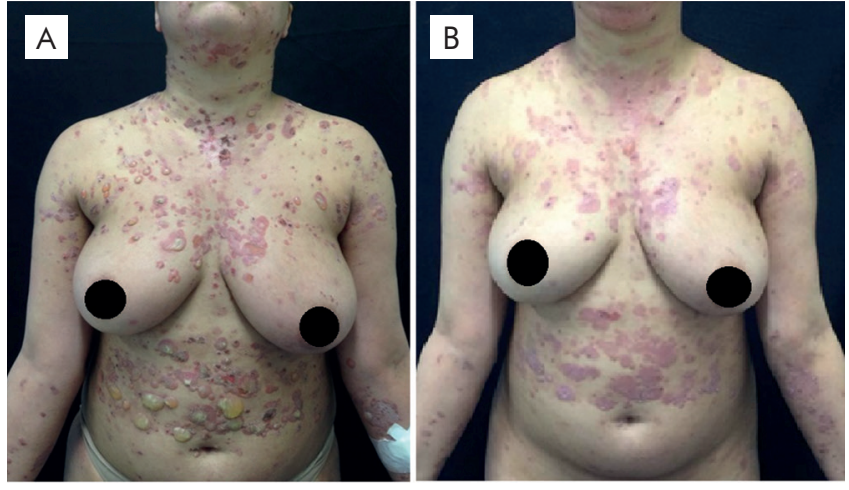

Figura 2 - (A) ) múltiplas bolhas tensas sobre base eritematosa antes da infusão de rituximab; (B) lesões residuais após infusão das quatro doses de rituximab.

com eosinófilos abundantes (Fig. 3) e depósito linear/tubular de $\lg G$ e C3 na junção dermo-epidérmica na imunofluorescência direta (Fig. 4). A imunofluorescência indireta em salt-split skin foi positiva com deposição de lgG no topo da bolha (Fig. 5), confirmando diagnóstico de penfigoide bolhoso.

Devido à extensão do quadro cutâneo, realizou pulsos de metilprednisolona $1 \mathrm{~g}$ intra-venoso em três dias consecutivos seguido de prednisolona $80 \mathrm{mg} /$ dia via oral, com repetição a cada sete dias. Foram surgindo novas lesões mas houve meIhoria no quarto dia após o término do terceiro ciclo $\left(31^{\circ}\right.$ dia de hospitalização) e recebeu alta hospitalar. Nesta data, como terapia imunossupressora poupadora de corticoide, optamos pelo metotrexato subcutâneo, pela sua disponibilidade no hospital e devido às restrições financeiras da paciente. A dose inicial de metotrexato $(12,5 \mathrm{mg} / \mathrm{semana})$ foi aumentada progressivamente até $20 \mathrm{mg} / \mathrm{semana}$, em paralelo com redução gradual da prednisolona oral, com controle clínico parcial das lesões cutâneas nas quatro semanas após a alta hospitalar.

Após quatro semanas, sob $40 \mathrm{mg} / \mathrm{dia}$ de prednisolona e

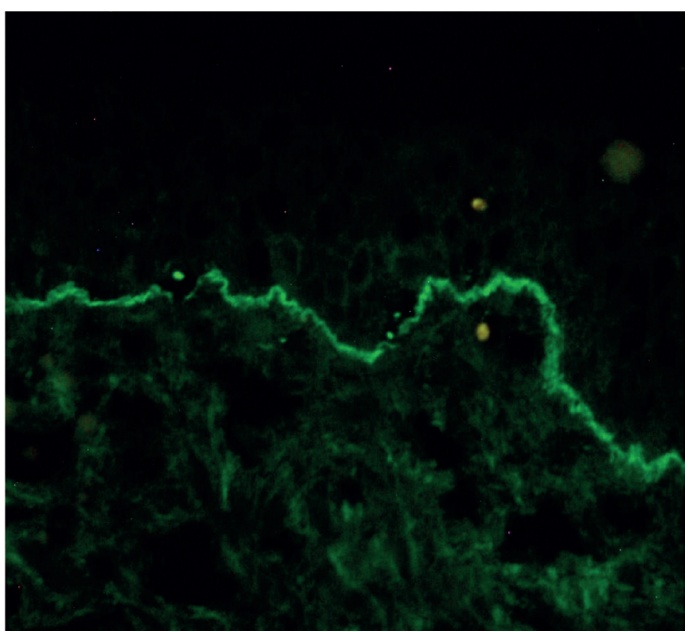

Figura 4 - Imunofluorescência direta com depósito linear de IgG e C3 na junção dermo-epidérmica (400x). 


\section{Caso Clínico}

$20 \mathrm{mg} /$ semana de metotrexato houve recorrência com novas lesões bolhosas cutâneas (Fig. 2a) e na mucosa oral. Optou-se, então, em internamento e após autorização do serviço de infectologia, pelo rituximab 500 mg e.v. uma vez por semana, durante quatro semanas consecutivas (dose total $2 \mathrm{~g}$ ). Observou-se remissão das lesões após a última dose de rituximab, na quarta semana de internamento (Fig. 2b) e não surgiram novas lesões nos 6 meses após a alta hospitalar. A carga viral manteve-se não detectável durante e após o tratamento com rituximab, não tendo sido repetidas as contagens de células CD4+ circulantes. Não observámos reativação das lesões de herpes genital, mas a profilaxia foi mantida durante todo o tratamento com rituximab.

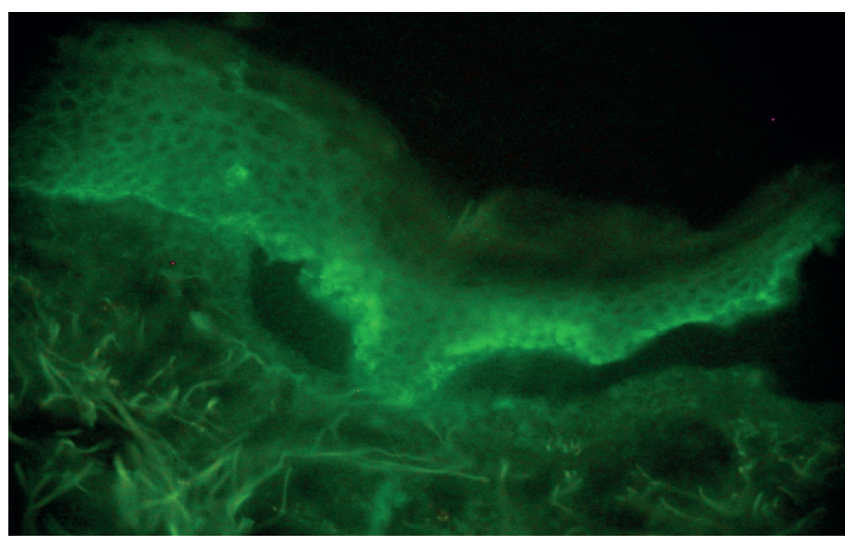

Figura 5 - Imunofluorescência indireta em salt-split skin com positividade para auto-anticorpos $\lg G$ no topo da bolha (100x).

\section{DISCUSSÃO}

As lesões de PB resultam sobretudo da ativação da cascata de complemento pelos autoanticorpos que se ligam aos antígenos BP 180/230, ${ }^{2}$ componentes dos hemidesmossomas dos ceratinócitos da membrana basal, seguido do recrutamento local de células inflamatórias e libertação de mediadores pró-inflamatórios e proteases que lesam a membrana basal ${ }^{3}$ e causam bolhas e vesículas subepidérmicas. A presença de lesões mucosas, observada na doente tanto na apresentação inicial como nas recorrências é pouco frequente no PB, mas frequentemente reportada nos pacientes $\mathrm{VIH}+{ }^{4}$

$A$ associação entre dermatose bolhosa autoimune, nomeadamente PB, e infecção pelo VIH é rara e ilustra que pacientes com infecção $\mathrm{VIH}$ podem sofrer doenças mediadas por auto-anticorpos órgão-específicos. ${ }^{5} \mathrm{O}$ papel direto das partículas virais, os complexos imunes gerados, a desregulação na interação de linfócitos $\mathrm{B} / \mathrm{T}^{6}{ }^{6}$ o mimetismo molecular, ${ }^{7}$ a ativação policlonal de linfócitos B poderiam favorecer a síntese de auto-anticorpos, que estão presentes em 23\% dos pacientes infectados pelo $\mathrm{VIH} .{ }^{8}$ Segundo lordache $\mathrm{L}$ et al estas doenças auto-imunes ocorrem sobretudo no contexto de bom controle imunológico (uso de TARV), como no presente caso, e mesmo durante a síndrome de reconstituição imune. ${ }^{9}$ Outros autores consideram esta associação casual, em face da prevalência significativa de infecção pelo VIH e a raridade da concomitância com doença autoimune. ${ }^{5}$

A refratariedade e maior gravidade do PB neste caso poderia estar associada à concomitância com a infecção VIH, cuja interação com o sistema imune, pode agravar ou melhorar as dermatoses bolhosas autoimunes, ${ }^{10}$ ou à idade jovem e a ausência de fatores precipitantes. Cruz et al, relatam o caso de um paciente masculino de 38 anos sem comorbidades, refratário às terapias convencionais e ao rituximab que faleceu aos 2,5 anos de doença, devido a complicações cardíacas. ${ }^{11}$

Com a refratariedade aos tratamentos instituídos, aventou-se a hipótese de neoplasia associada, descartada após exames complementares e avaliação multidisciplinar. A hipótese de PB induzido por fármaco foi excluída pela anamnese, uma vez que não foi introduzida nenhuma nova medicação nos seis meses que antecederam o início das lesões.

De acordo com últimas recomendações internacionais, a corticoterapia em pulsos usada nesta paciente devido à exuberância do quadro não é a conduta inicial na abordagem do PB. Segundo o Consenso Europeu de 2015,12 a primeira linha de tratamento inclui corticosteroides tópicos de alta potência como o propionato de clobetasol 0,05\% creme (30-40 g/dia), em duas aplicações diárias em toda a superfície corporal, poupando a face. Os corticosteroides orais, como a prednisona $1 \mathrm{mg} / \mathrm{kg} /$ dia, são outra opção terapêutica mas associada a maior mortalidade e efeitos adversos. ${ }^{13}$

Além do metotrexato outros imunossupressores como micofenolato mofetil, azatioprina ou imunoglobulina intravenosa (IVIG) são uma alternativa segura e eficiente em pacientes com infecção $\mathrm{VIH} .{ }^{14}$ Devido à sua indisponibilidade e à refratariedade do quadro optou-se pelo rituximab, um anticorpo monoclonal anti-CD20 que reduz a população circulante de linfócitos B CD20+, responsáveis pela produção de auto-anticorpos patogénicos. $O$ seu efeito prolongado pode ser atribuído à formação de uma linhagem naive de linfócitos B. ${ }^{15}$ Alguns autores consideram o rituximab benéfico nos casos de $\mathrm{PB}$ refratários e/ ou rapidamente progressivos, levando a uma remissão mais prolongada da doença e a uma melhoria clínica mais rápida, 16 como na paciente relatada. Shetty $S$ et al mostraram que 11 dos 16 casos de PB (69\%) tratados com rituximab obtiveram resposta completa, enquanto dois foram refratários e três faleceram devido a sepsis (2) e efeitos cardíacos (1),17 e de 12 indivíduos acompanhados durante 6 anos, a resolução completa ocorreu em média aos 4,6 meses, havendo recaída em dois doentes, que responderam bem à infusão adicional de rituximab. ${ }^{18}$

$\mathrm{O}$ uso de rituximab em paciente $\mathrm{VIH}+$ é recorrente nos protocolos de linfoma não-Hodgkin e no linfoma difuso de grandes células B em que um estudo clínico prospectivo com 1546 pacientes mostrou que a adição de rituximab ao esquema de quimioterapia $\mathrm{CHOP}$ foi benéfico e não aumentou a mortalidade por complicações infecciosas ${ }^{19}$ tal como no presente caso. Contudo, pacientes com contagem CD4+ < 50 células/ $\mu \mathrm{l}$ devem realizar profilaxia antimicrobiana, administração de fator estimulador de colónias de granulócitos e tratamento das infecções oportunistas, além do uso de TARV. ${ }^{20}$ 


\section{Caso Clínico}

\section{CONCLUSÃO}

O PB é uma doença crónica com exacerbações e remissões, em que comorbilidades como a infecção pelo VIH tornam o manejo terapêutico um desafio para os dermatologistas. A interferência do rituximab na imunodeficiência dos doentes $\mathrm{VIH}+$ não está completamente elucidado, pelo que mais estudos são necessários para avaliar a sua segurança nestes pacientes e a sua eficácia nas doenças bolhosas auto-imunes concomitantes, como o PB.

Conflitos de interesse: Os autores declaram não possuir conflitos de interesse.

Suporte financeiro: $O$ presente trabalho não foi suportado por nenhum subsídio ou bolsa.

Confidencialidade dos dados: Os autores declaram ter seguido os protocolos do seu centro de trabalho acerca da publicação dos dados de doentes.

Protecção de pessoas e animais: Os autores declaram que os procedimentos seguidos estavam de acordo com os regulamentos estabelecidos pelos responsáveis da Comissão de Investigação Clínica e Ética e de acordo com a Declaração de Helsínquia da Associação Médica Mundial.

Consentimento dos Doentes: Obtido.

Conflicts of interest: The authors have no conflicts of interest to declare.

Financing Support: This work has not received any contribution, grant or scholarship.

Confidentiality of data: The authors declare that they have followed the protocols of their work center on the publication of data from patients.

Protection of human and animal subjects: The authors declare that the procedures followed were in accordance with the regulations of the relevant clinical research ethics committee and with those of the Code of Ethics of the World Medical Association (Declaration of Helsinki).

Patients consent: Obtained.

\section{REFERÊNCIAS}

1. ReferênciasTarazona MJM, Unterstell N, Mota da Silva AN, Bressan AL, Gripp AC. Penfigoide bolhoso e doença neurológica: casuística de um Serviço de Dermatologia. An Bras Dermatol. 2015; 90: 282-4.

2. Kasperkiewicz M, Zillikens D, Schmidt E. Pemphigoid diseases: pathogenesis, diagnosis, and treatment. Autoimmunity. 2012; 45: 55-70.

3. Verraes S, Hornebeck W, Polette M, Borradori L, Bernard $P$. Respective contribution of neutrophil elastase and matrix metalloproteinase 9 in the degradation of BP180 (type XVII collagen) in human bullous pemphigoid. J Invest Dermatol. 2001; 117: 1091-6.

4. Donoso-Hofer F. Lesiones orales asociadas con la enfermedad del virus de immunodeficiencia humana en pacientes adultos, una perspectiva clínica. Rev Chilena Infectol. 2016; 33 (Suppl 1): 27-35.

5. Dipankar De, Amrinder JK, Bishan DR, Tarun N. Bullous eruption in a patient infected with the human immunodeficiency virus. Skinmed. 2008:7; 98-101.

6. Stahl D, Lacroix-Desmazes S, Misra N, Karmochkine M,
Kaveri SV, Costagliola D, et al. Alterations of self-reactive antibody repertoires in HIV disease: an insight into the role of $\mathrm{T}$ cells in the selection of autoreactive $\mathrm{B}$ cells. Immunol Lett. 2005; 99: 198-208.

7. Tsiakalos A, Routsias JG, Kordossis T, Moutsopoulos HM, Tzioufas AG, Sipsas NV. Fine epitope specificity of anti-erythropoietin antibodies reveals molecular mimicry with HIV-1 p17 protein: a pathogenetic mechanism for HIV-1 related anemia. J Infect Dis. 2011; 204: 902-11.

8. Savige JA, Chang L, Horn S, Crowe SM. Anti-nuclear, anti-neutrophil cytoplasmic and anti-glomerular basement membrane antibodies in HIV-infected individuals. Autoimmunity. 1994; 18: 205-11.

9. lordache L, Launay O, Bouchaud O, Jeantils V, Goujard $\mathrm{C}$, Bove $\mathrm{F}$, et al. Autoimmune diseases in HIV-infected patients: 52 cases and literature review. Autoimmun Rev. $2014 ; 13: 850-7$.

10. Lateef A, Packles MR, White SM, Don PC, Weinberg JM. Pemphigus vegetans in association with human immunodeficiency virus. Int J Dermatol. 1999; 38: 778-81.

11. Cruz MJ, Santos P, Morais P, Barreto F, Azevedo F. Refractory bullous pemphigoid with fatal outcome in a Young patient. Int J Dermatol. 2013; 52: 601-2.

12. Feliciani C, Joly P, Jonkman MF, Zambruno G, Zillikens D, loannides $D$,et al. Management of bullous pemphigoid: the European Dermatology Forum consensus in collaboration with the European Academy of Dermatology and Venereology. Br J Dermatol. 2015; 172: 867-77.

13. Joly P, Roujeau JC, Benichou J, Picard C, Dreno B, Delaporte $E$, et al. A comparison of oral and topical corticosteroids in patients with bullous pemphigoid. N Engl J Med. 2002; 346:321-7.

14. Cabete J, Fidalgo A, Páris FR, Santos G, Serrão V. Intravenous immunoglobulin for the treatment of quetiapin-induced bullous pemphigoid in an HIV-infected patient. J Am Acad Dermatol. 2013: AB1 13.

15. Joly $P$, Mouquet $H$, Roujeau JC, D'Incan M, Gilbert D, Jacquot $S$, et al. A single cycle of rituximab for the treatment of severe pemphigus. N Engl J Med. 2007; 357: 545-52.

16. Bomm L, Sodré JL, Fracaroli TS, Bressan AL, Gripp AC. Uso off label do rituximab na dermatologia: tratamento dos pênfigos. An Bras Dermatol. 2013; 88: 687-9.

17. Shetty S, Ahmed AR. Treatment of bullous pemphigoid with rituximab: critical analysis of the current literature. J Drugs Dermatol. 2013;12: 672-7.

18. Ahmed AR, Shetty S, Kaveri S, Spigelman ZS. Treatment of recalcitrant bullous pemphigoid (BP) with a novel protocol: A retrospective study with a 6-year follow-up. J Am Acad Dermatol. 2016; 74: 700-8.

19. Barta SK, Xue X, Wang D, Tamari R, Lee JY, Mounier N, Kaplan LD et al. Treatment factors affecting outcomes in HIV-associated non-Hodgkin lymphomas: a pooled analysis of 1546 patients. Blood. 2013; 122: 3251-62.

20. Brunnberg $U$, Hentrich M, Hoffmann C, Wolf T, Hubel K. HIV-associated malignant lymphoma. Oncol Res Treat. 2017; 40: 82-87. 